\title{
RUPTURA VESICAL POR CISTITIS ENFISEMATOSA, UNA CAUSA RARA DE ABDOMEN AGUDO: REPORTE DE UN CASO.
}

\author{
BLADDER RUPTURE ON EMPHYSEMATOUS CYSTITIS, A RARE CAUSE OF ACUTE
} ABDOMEN: CASE REPORT

${ }^{1}$ Residente del cuarto año de cirugía general, Secretaría de Salud, México.

2 Residente del tercer año de cirugía general, Secretaría de Salud, México.

${ }^{3}$ Cirujano General/ Secretaría de Salud (México)

Correspondencia a:

Daniel Alejandro Reyes García

Correo: Daniel Alejandro Reyes García

ORCID: https://orcid.org/00000003-4554-5138

Palabras clave: cistitis, ruptura, neumoperitoneo.

Keywords: urinary cystitis, rupture, pneumoperitoneum.

Procedencia y arbitraje: no comisionado, sometido a arbitraje externo.

Recibido para publicación: 20 de abril de 2020 Aceptado para publicación: 31 de diciembre de 2020

Citar como:

Reyes García DA, López Trinidad SA, Luna Meza K. Ruptura vesical por cistitis enfisematosa, una causa rara de abdomen agudo: reporte de un caso. Rev Cient Cienc Med 2020; 23(1): 258-261

\section{RESUMEN}

La cistitis enfisematosa es una complicación de las infecciones del tracto urinario de baja incidencia, así como una rara causa de perforación vesical. Generalmente se presenta en pacientes diabéticos y se caracteriza por la presencia de gas en el lumen o pared de la vejiga; puede ser asintomática o llegar a causar un estado crítico de choque séptico. Se debe tener presente este diagnóstico diferencial en pacientes inmunosuprimidos con antecedentes de infecciones en las vías urinarias, para así poder solicitar los exámenes complementarios necesarios y realizar un adecuado diagnóstico. Se presenta a un paciente femenino de 59 años, diabética no controlada, con cistitis enfisematosa complicada con perforación vesical con imágenes típicas por tomografía, y su manejo quirúrgico.

\section{ABSTRACT}

Emphysematous cystitis is a complication of urinary tract infection a low incidence pathology, and a rare cause of bladder perforation. Generally occurs in diabetic patients and its characterized by the presence of gas in the lumen or wall of the urinary bladder; it could be an asyntomatic case or be the cause of a critical state of septic shock. We need to keep in mind this differential diagnosis in inmunosuppresed patientis with previous history of urinary tract infection, in order to request specific complementary tests and get the adequate diagnosis. Presents a 59 year old female case, diabetic patient who presents emphysematous cystitis complicated with urinary bladder perforation, classic tomography images and the surgical management.

\section{INTRODUCCIÓN}

a cistitis enfisematosa en una infección -poco frecuente del tracto urinario, suelen aparecer bacterias aerobias en la pared vesical y en los tejidos adyacentes, es una enfermedad potencialmente grave que requiere realizar un diagnóstico temprano, así como establecer un tratamiento lo más pronto posible.' Se sabe que el aire en el tracto urinario no es especifico de esta patología ya que puede tener otros orígenes como: por instrumentación, fístulas a víscera hueca, infarto de tejidos con necrosis o infección. Es una enfermedad que presenta baja incidencia. El cuadro clínico puede ir desde estar asintomático hasta el choque séptico. ${ }^{2}$

Es más común en la población geriátrica entre la $6^{\mathrm{a}}$ y $8^{\mathrm{a}}$ década de la vida, observándose una mayor incidencia en el género femenino
$(1,8: 1)$. Se observa mayor predisposición en pacientes diabéticos (70-80\%), y en menor medida en pacientes con infecciones urinarias de repetición, portadores de catéteres u obstrucción urinaria. ${ }^{3,4}$

\section{DESARROLLO}

Paciente femenino de 59 años, antecedente de DM II de 10 años de diagnóstico en tratamiento con Metformina 500 mg tabletas vía oral 1 cada 12 horas y Glibenclamida $5 \mathrm{mg}$ tabletas vía oral 1 cada 12 hr, con mal apego y mal control de su enfermedad.

Refiere iniciar 1 semana previa a ser internada, disuria y dolor en hipogastrio, acudiendo a un médico particular el cual le indica ketorolaco 
en tabletas de 10 mg vía oral 1 cada 8 hr y Trimetoprim / Sulfametoxazol, tabletas de $160 \mathrm{mg}$ /800 mg vía oral durante los 2 días siguientes, no refiere mejoría.

Acude a urgencias encontrándose con astenia, adinamia, fiebre, dolor abdominal, alteración del estado mental y datos de inestabilidad hemodinámica. A la exploración física: desorientada en las 3 esferas; abdomen tenso, hipertimpánico, sin ruidos peristálticos; facie dolorosa a la palpación abdominal en 4 cuadrantes con rebote positivo, presencia de piuria por sonda Foley.

Se realiza Tomografía axial computarizada (TAC) de abdomen simple encontrando: derrame pleural mínimo en bases pulmonares, neumoperitoneo, líquido perihepático en correderas parietocólicas y hueco pélvico, se aprecia gas intravesical. (Fig. 1 y 2)

En los laboratorios iniciales encontramos: lactato sérico de $4.1 \mathrm{mmol} / \mathrm{L}$, leucocitosis de 25.00 $\mathrm{K} / \mathrm{uL}$, glicemia $720 \mathrm{mg} / \mathrm{dL}$, creatinina $3.9 \mathrm{mg} / \mathrm{dL}$, BUN $62 \mathrm{mg} / \mathrm{dL}$, sodio $99 \mathrm{mEq} / \mathrm{L}$, potasio de 2.9 $\mathrm{mEq} / \mathrm{L}$.

EGO: $p H$ 6.0, leucocitos - Proteinas ++++ glucosa + cetonas +++ nitritos -, Hemoglobina +++ , urobilinógeno 0.2 UE, eritrocitos incontables, bacterias regulares, células epiteliales escasas, leucocitos incontables.

Se inicia de inmediato antibioticoterapia IV a base de imipenem $500 \mathrm{mg}$ cada 12 horas y metronidazol 500mg cada 8 hrs, además de manejo hídrico agresivo con administración de cristaloides IV.

Se realiza una laparotomía exploradora una hora después de su ingreso a urgencias encontrando abundante gas a la apertura de peritoneo y orina, además, se halla plastrón vesico- sigmoides- epiplón mayor - íleon terminal, se diseca encontrando perforación vesical con necrosis de la cúpula vesical, se reavivan bordes y se realizan cierre primario en dos planos con ácido poliglicólico 3-0, se colocan drenaje penrose por contrabertura. (Fig. 3 y 4)

Se recaba urocultivo el cual se había solicitado previamente a su llegada a urgencias reportando Escherichia coli y Candida alficans.

Paciente ingresa en postoperatorio a Unidad de Cuidados Intensivos con diagnóstico de choque séptico de origen urinario, dando manejo analgésico IV con tramadol 50mg cada 8 hrs y ketorolaco $30 \mathrm{mg}$ cada $8 \mathrm{hrs}$, además de realización de irrigación con 200cc de solución fisiológica cada 8 horas por sonda Foley, durante los 3 días posteriores se obtiene aumento de diuresis por sonda Foley hasta límites normales con disminución de gasto por Penrose de aspecto seroso mínimo, al 5to día se egresa a piso y se inician ejercicios vesicales, se da de alta del hospital al 7mo día (sin drenajes abdominales), indicando continuar ejercicios vesicales y se cita a las dos semanas para retiro de sonda Foley, con citas subsecuentes sin complicaciones.

\section{DISCUSIÓN}

En el caso expuesto se cumple lo que expone Garma AG, et al., que indica que para que exista una perforación vesical debe existir una patología subyacente, en este caso cistitis enfisema-

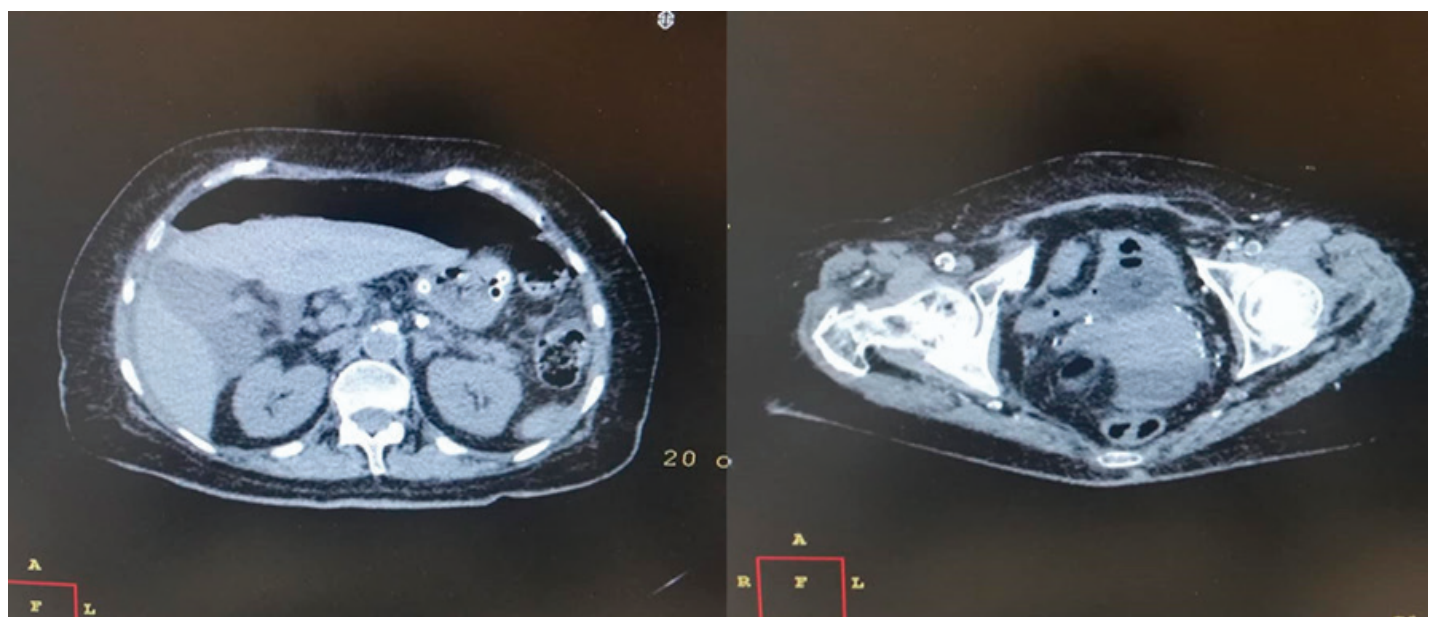

Figura 1: Figura 1A En TAC simple de abdomen y pelvis, se halla neumoperitoneo, además de líquido libre perihepático. Figura $1 B$ Se aprecia aire dentro de la vejiga y en la pared vesical. 


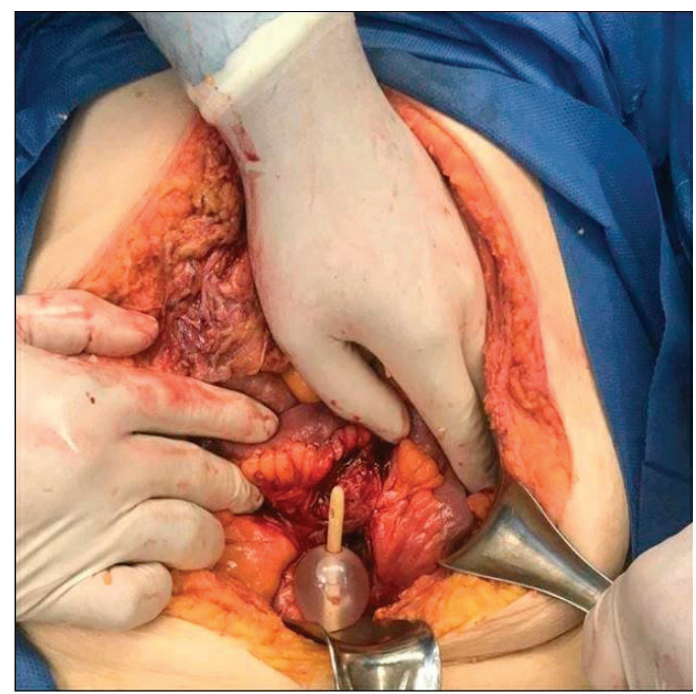

Figura 2: Ruptura vesical, sonda Foley intraperitoneal.

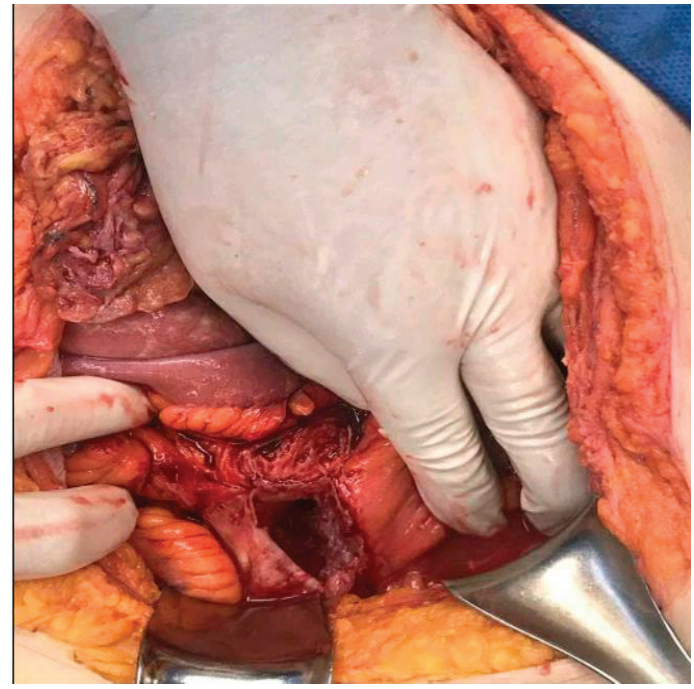

Figura 3: Se resecan bordes necróticos de cúpula vesical.

tosa, y su forma de presentación más frecuente es un paciente con un cuadro de abdomen agudo. ${ }^{5}$ La cistitis enfisematosa afecta con mayor frecuencia a mujeres respecto a los hombres (2:1) y se suscita en pacientes inmunodeprimidos o con obstrucción de la vía urinaria.1 Revisando la literatura sabemos que las cistitis enfisematosa es una infección del tracto urinario inferior muy poco frecuente, caracterizada por aire en la pared vesical producido por bacterias $u$ hongos, y encontramos que esta se puede sospechar ante la presencia de la tríada clínica compuesta por: paciente de edad avanzada, del

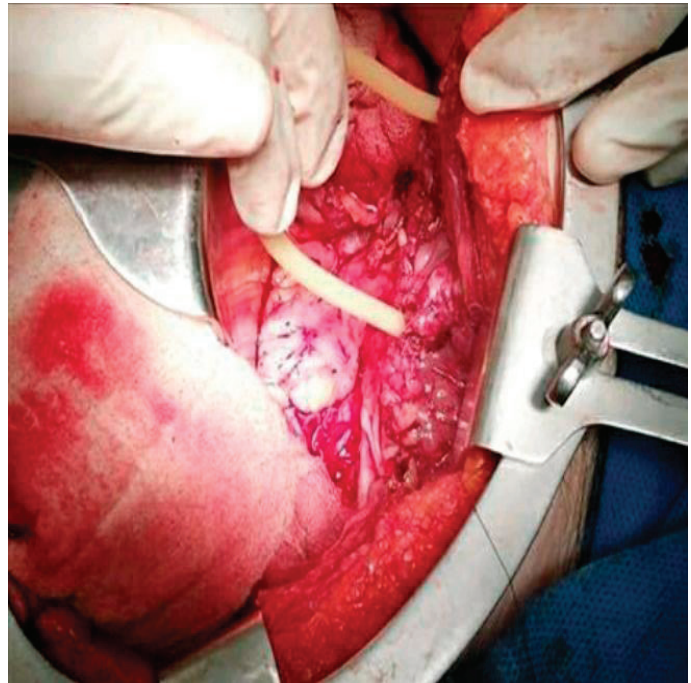

Figura 4: Cierre vesical en 2 planos utilizando sonda Foley como referencia.

género femenino y con antecedentes de diabetes mellitus tipo II. Se debe tener una temprana y fuerte sospecha diagnóstica en pacientes sépticos con antecedente de disuria y dolor abdominal bajo. La neumaturia pudiera ser un signo patognomónico pero es raro. ${ }^{6,7}$

Debido a que el cuadro clínico es variable y no especifico, es necesario apoyarnos en métodos de imagen para realizar el diagnostico. La radiografía es de gran utilidad y de bajo costo, siendo el hallazgo de aire en el contorno vesical lo que nos llevaría a sospechar el diagnostico, en ocasiones se describe la pared de la vejiga dando una imagen en "cuentas de collar" o "arenosa". La TAC nos dará más datos pero con un costo mayor, pudiendo descartar los diagnósticos diferenciales como fistula colovesical, abscesos intrabdominales, enfermedad neoplásica y hasta pielonefritis enfisematosa así como también encontrar complicaciones como neumoperitoneo y urinoma en caso de ruptura vesical.8 Ante la sospecha de una ruptura vesical se debe realizar una cistografía como nos menciona Garma AG, et al. ${ }^{5}$

El pronóstico de ambas entidades es muy malo. El tratamiento de la cistitis enfisematosa se basa en antibioticoterapia a base de quinolonas, carbepenémicos, penicilinas junto a inhibidores de betalactamasas o cefalosporinas de la $3^{\text {a }}$ generación y derivación urinaria. ${ }^{9}$ La cirugía es rara, en la cual en el caso de encontrar una ruptura vesical secundaria a cistitis necrotizan- 
te a consecuencia de una cistitis enfisematosa no tratada, está indicado un manejo quirúrgico urgente que consiste en realizar una cistectomía de la porción necrosada con cierre primario vesical, colocación de sonda Foley y drenajes abdominales. ${ }^{5}$ Los organismos más frecuentemente encontrados en cultivos de infecciones complicadas de vías urinarias son Escherichia coli (65\%), Enterococcus spp (11\%), Klebsiella pneumonie (8\%) y Candida albicans (7\%). ${ }^{10}$

como nos comenta Qin Y, et al., la cistitis enfisematosa tiene un pronóstico favorable al ser diagnosticada de manera oportuna, pero como en nuestro caso presentado, un diagnóstico en etapas avanzadas puede llegar a evolucionar a la presencia de una ruptura vesical o incluso una pielonefritis enfisematosa que conllevarían a realizar un manejo quirúrgico junto a antibioticoterapia prolongada. ${ }^{11}$

\section{CONCLUSIÓN}

El diagnóstico de cistitis enfisematosa/ruptura vesical debe ser temprano, ya que es una patología rara y de pronóstico devastador. Debemos tener en cuenta este diagnóstico diferencial principalmente en pacientes de la tercera edad, diabéticos, con antecedentes de sintomatología urinaria y con datos clínicos de irritación peritoneal. Para poder realizar el diagnóstico de esta enfermedad es necesario siempre apoyarse en estudios de imagen principalmente en una tomografía axial computarizada. Su manejo se basa en reanimación hemodinámica, antibioticoterapia y derivación urinaria, en el caso de la ruptura vesical, el tratamiento quirúrgico es urgente, basándose en cierre primario vesical. En nuestro paciente afortunadamente se realizó el diagnóstico temprano lo que nos llevó a brindarle un tratamiento adecuado con lo cual evolucionó favorablemente.

\section{REFERENCIAS}

1.Martínez HI, Flores-Palacios JO, Ricardez AA, Jiménez LA. Cistitis enfisematosa. Reporte de un caso. Rev Mex Urol [Internet]. 2018 ene-feb [Citado el 1 de Marzo del 2020];78(1):44-50. Disponible en: https://www.revistamexicanadeurologia.org.mx/index.php/ rmu/article/view/129

2.Vilchis MA, Grimaldo AA, Ibáñez JA, Feria MA, García MA, Peña $A$, et al. Cistitis enfisematosá clásica. Revista mexicana de urología [Internet]. 2010 [Citado el 1 de Marzo del 2020];70(6):376-379. Disponible en: https://www. elsevier.es/es-revista-revistamexicana-urologia-302-articulo-cistitis-enfisematosaclasica-X2007408510905590.

3. Hudnall MT, Jordan BJ, Horowitz J, Kielb S. A case of emphysematous cystitis and bladder rupture. Urology case reports [lnternet]. 2019 [Citado el 1 de Marzo del 2020]. Disponible en: https://www.ncbi.nlm. nif.gov/pmc/articles/PMC6562318\%.

4.Thomas AA, Lane BR, Thomas AZ, Remer EM, Campbell SC, Shoskes DA Emphysematous cystitis: A review of 135 cases. BJU Int [Internet]. 2007 [Citado el 01 de Marzo de 2020];100(1):17-20. Disponible en: https://doi.org/10.1111/j.1464-410X.2007.06930.x

5.Garma AG, Fernández E, Gutiérrez FJ, Sandoval JP, Luna A. Perforación vesical por cistitis enfisematosa. Acta Médica Grupo Ángeles [Internet]. 2011 [Citado el 1 de Marzo de 2020];9 (2): 96-99. Disponible en: https://www.medigraphic.com/pdfs/actmed/am-2011/ am112f.pdf
6.May T, Stein A, Molnar R, Dekel Y. Demonstrative Imaging of Emphysematous Cystitis, Urology case reports [Internet]. 2016 [Citado el 1 de Marzo de 2020]. Disponible en: DOI: 10.1016/j.eucr.2016.03.001.

7. Dekeyzer S, Houthoofd B. Emphysematous Cystitis. Journal of the Belgian Society of Radiology [lnternet]. 2018 [Citado el 1 de Marzo de 2020]. Disponible en: DOI: http://doi.org/10.5334/j6sr.1192.

8.Roels $\mathrm{P}$, Decaestecker $\mathrm{K}$, De Visschere $\mathrm{P}$. Spontaneous bladder wall rupture due to emphysematous cystitis. J Belg Soc Radiol [Internet]. 2016 [Citado el 1 de Marzo de 2020]; 100:83. Disponible en: DOI: 10.5334 / j6r-6tr.1151.

9. Cerquera D, Manrique L, Corredor H, Varela R. Cistitis Enfisematosa: abordaje clínico y terapeútico. Urol Colomb [Internet]. 2016 [Citado el 1 de Marzo 2020];25 (1): 46-49. Disponible en: https://doi. org/10.1016/j.uroco.2015.12.004

10. Flores A, Walker J, Caparon M, Hultgren S. Urinary Tract Infections: epidemiology, mechanism of infection and treatment options. Nat Rev Microbiol [Internet]. 2015[ Citado el 1 de Marzo de 2020];13 (5): 269-284. Disponible en: https://doi.org/10.1038/ nrmicro3432

11.Qin Y, Tulsidas $H$, Jaufeerally F, Leon Tan RK. Emphysematous Cystitis Complicated by Urinary Bladder Perforation: A case report. Proceedings of Singapore Healthcare. 2012 Jun; 21(2). Disponible en: DOI: $10.1177 / 201010581202100208$ 